\title{
Corticosteroid Derivative Effect to Pregnant Rats on the Brain of Their Offspring
}

\author{
Irina V. Nikolaeva ${ }^{1, *}$, Tuyaara P. Sivtseva ${ }^{1}$ and Elena V. Pshennikova ${ }^{1}$ \\ ${ }^{1}$ M.K. Ammosov North-Eastern Federal University, Medical Institute, 27, Oyunsky St., 677013, Yakutsk, Russia \\ ${ }^{*}$ Corresponding author. Email: iv.nikolaeva@s-vfu.ru
}

\begin{abstract}
The work investigated the immediate and distant consequences of the introduction of Cortineff. Cortineff, as a derivative of corticosteroids, has both mineral- and glucocorticoid properties. Moreover, its predominant effects are mineralocorticoid. The injection of Cortineff to pregnant rats caused a number of brain features of their offspring. In one-day rats, they included an increase in the thickness of the cortex and its first layer in the anteroposterior and parietal lobe proper, the density of neurons in the second layer of the anteroposterior lobe, as well as in the II and V layers of the parietal lobe proper, an increase in the size of the nuclei of neurons of the $\mathrm{V}$ layer of the anteroposterior lobe and hippocampus. In animals of the experimental group at the age of 40 , morphometric differences in the parameters characterizing the neocortex were revealed. They manifested themselves with a larger thickness of the anteroposterior lobe and its first layer. The density of neurons in layer II of the anteroposterior and parietal lobe itself was increased in experimental animals. it is believed that their total number in the cortex was increased compared to the control one. At the same time, the large thickness of the first layer, formed mainly by the processes of deep neurons, can indicate a greater intensity of its development. Reflecting the higher synthetic activity of neocortex neurons, one can consider the reliably large sizes of the nuclei of the neurons of the II layer of the parietal lobe itself and the nuclei of the neurons of the field SA1 hippocampus.
\end{abstract}

Keywords: Corticosteroid derivative effect, Cortineff, rats, brain

\section{INTRODUCTION}

Hormones are important factors affecting embryonic brain organogenesis. They can have both regulatory and programming effects on its brain development affecting the embryo/fetus, [1-3]. In the early stages of ontogenesis, corticosteroid hormones are an important factor for the growth and differentiation of different systems of the body and, first of all, the CNS, when they affect the survival, development and programmed death of neurons [4-6]. In this regard, the issue of both the immediate and delayed effects of corticosteroid hormone administration is of considerable interest. Cortineff is a medication for replacing mineral-corticoid insufficiency produced in tablets. In Russia, Cortineff is used, containing $0.1 \mathrm{mg}$ of acetate fludrocortisone in one tablet [7].

The aim of the study: To study the effect of Cortineff to pregnant rats on the gravimetric, morphometric and physiological indicators of brain development of their one - and 40-day offspring.

\section{MATERIALS AND METHODS}

On the 18th day of pregnancy, 7 female rats were administered Cortineff $0.1 \mathrm{mg} / \mathrm{kg}$ once through a gastric probe. The control was the offspring of 6 intact female rats. Slaughter of control and experimental animals was carried out simultaneously. In all groups, gravimetric indicators were determined on electronic scales: body weight, brain weight, hemisphere. The left hemisphere of one-day and 40-day rats was fixed in Carnoy's fluid, poured into paraffin, and sections $7 \mu \mathrm{m}$ thick were prepared, which were stained with $1 \%$ methylene blue. Morphometric study was carried out on a series of medications of the occipitoanterior (OLP) and the parietal lobe proper (PLP). To determine the thickness of the cerebral cortex and its I layer, measurement was carried out in 3 sections, using an eyepiece-micrometer 
MOV-15. To determine the density of neurons in the II and $\mathrm{V}$ layers of the neocortex, the number of cells in 5 standard fields of view of each layer was calculated using the ocular lens $\mathrm{x} 10$, with lens increase in $\mathrm{x} 40$. Measurement of the cross-sectional area of the nuclei and cytoplasm of pyramid neurons II and V layers of the occipitoanterior and parietal lobe proper, as well as the SA1 field of the hippocampus was carried out by computer morphometry. 25 cells were measured in each of these zones.

TMJ indicators were estimated by the parameters of recording the behavior of 30-day-old rats in the original computer program Rat Test Version 1.0. During the experiment, each animal was placed in the PLP, where the total time and number of "elementary" behavioral acts were recorded for 3 minutes: hanging, posts, grooming, sniffing, movements, entering the open and closed sleeves of the labyrinth, inaction. Integral characteristics were determined from the listed components of behavior: research activity and anxiety level [8]. Statistical data processing was carried out by Statistica program. Differences were considered reliable in $\mathrm{p}<0,05$.

\section{RESULTS AND DISCUSSION}

The one-day offspring of females who had Cortineff injections had a statistically significantly large body weight, with almost equal absolute brain weight. The consequence of this was a decrease in its relative mass in experimental animals. Morphometric examination of neonatal cortex revealed the following differences in experimental animals: larger than in control, the thickness of the cortex and its I layer in both the occipitoanterior and the parietal lobe proper, a greater density of neurons in the II layer of the occipitoanterior lobe and in the II and $\mathrm{V}$ layers of the parietal lobe proper, large nucleus sizes in neurons of the $\mathrm{V}$ layer of the occipitoanterior lobe and nuclei of the hippocampus neurons (Table 1). The combination of these differences can be regarded as evidence of the greater activity of synthetic processes in neurons, the accelerated development of these cells in the cortex of the brain. At the same time, the high neuronal location density appears to be a consequence of the greater proliferative activity of their progenitors or/and less elimination thereof.

At the age of 40, animals of the experimental group had no differences in body weight, brain, hemisphere. The morphometric differences in the neocortex were manifested by the greater thickness of the anteropteric lobe and its Ist layer. Since the density of neurons in the IId layer of the anteroposterior and parietal lobe was also increased in experimental animals, it is believed that their total number in the cortex was increased compared to the control. The large thickness of the Ist layer, formed by deep neurons processes, can also indicate a greater intensity of their formation. Reflecting the higher synthetic activity of neocortex neurons, one can consider the reliably large sizes of the nuclei of the neurons of the IId layer of the parietal lobe itself and the hippocampal neurons (Table 2). The revealed effects of Cortineff administration can be associated with both the anabolic properties of mineralocorticoids and the direct effect of the drug on cells of the forming brain that have receptors to these hormones. The concentration of nucleic acids in the brain of the experimental group was significantly increased in the nucleoli, nuclei and cytoplasm of neurons in layers II and V of both the anteroparietal and parietal lobes proper, as well as in the hippocampus (Table 3 ).

Table 1. Cortineff effect on pregnant rats on gravimetric and morphometric cerebral indices of their one-day offspring

\begin{tabular}{|c|c|c|}
\hline${ }^{3}$ & $\begin{array}{l}\text { Intact } \\
(n=20)\end{array}$ & $\begin{array}{l}\text { Cortineff } \\
\text { injection } \\
(n=28)\end{array}$ \\
\hline Body mass, $\Gamma$ & $5.5 \pm 0.11$ & $6.1 \pm 0.12^{*}$ \\
\hline Brain mass, abs., mg & $245 \pm 5.2$ & $253 \pm 4.3$ \\
\hline Hemispheric mass, mg & $81 \pm 1.4$ & $83 \pm 1.7$ \\
\hline Brain mass, el., mg/g & $44 \pm 0.7$ & $41 \pm 0.3^{*}$ \\
\hline Thickness of brain cortex OLP, $\mu \mathrm{m}$ & $587 \pm 9.3$ & $638 \pm 10.3^{*}$ \\
\hline Thickness of 1 OLP layer, $\mu \mathrm{m}$ & $57 \pm 1.5$ & $63 \pm 1.2^{*}$ \\
\hline \multicolumn{3}{|l|}{$\begin{array}{l}\text { Number of neurons in OLP field of } \\
\text { view: }\end{array}$} \\
\hline -II layer & $26.4 \pm 0.43$ & $28.7 \pm 0.30$ * \\
\hline -V layer & $8.3 \pm 0.17$ & $8.8 \pm 0.20$ \\
\hline \multicolumn{3}{|l|}{ Section area, $\mu \mathrm{m} 2, \mathrm{OLP}$} \\
\hline - nuclei of neurons of II layer & $1.6 \pm 0.06$ & $1.6 \pm 0.04$ \\
\hline - nucleus of layer II neurons & $24.9 \pm 0.53$ & $24.6 \pm 0.66$ \\
\hline - nuclei of neurons of $\vee$ layer & $2.0 \pm 0.06$ & $2.0 \pm 0.04$ \\
\hline - nucleus of $\vee$ layer neurons & $34.6 \pm 0.61$ & $36.7 \pm 0.59 *$ \\
\hline Brain cortex thickness PLP, $\mu \mathrm{m}$ & $508 \pm 11.1$ & $572 \pm 11.0^{*}$ \\
\hline Thickness of 1 PLP layer, $\mu \mathrm{m}$ & $54 \pm 1.2$ & $59 \pm 1.2^{*}$ \\
\hline \multicolumn{3}{|l|}{$\begin{array}{l}\text { Number of neurons in PLP field of } \\
\text { view: }\end{array}$} \\
\hline -II layer & $25.7 \pm 0.36$ & $28.0 \pm 0.37$ * \\
\hline -V layer & $8 \pm 0.17$ & $9.1 \pm 0.15^{\star}$ \\
\hline \multicolumn{3}{|l|}{ Section area, $\mu \mathrm{m} 2, \mathrm{PLP}$} \\
\hline - nuclei of neurons of II layer & $1.6 \pm 0.06$ & $1.7 \pm 0.05$ \\
\hline - nucleus of layer II neurons & $24.5 \pm 0.50$ & $25.9 \pm 0.86$ \\
\hline - nuclei of neurons of $V$ layer & $2.0 \pm 0.07$ & $2.0 \pm 0.05$ \\
\hline - nucleus of $\vee$ layer neurons & $35.2 \pm 0.73$ & $36.2 \pm 0.90$ \\
\hline -hippocampal neuronal nuclei & $2.1 \pm 0.07$ & $2.2 \pm 0.06$ \\
\hline -hippocampal neuronal nuclei & $36.1 \pm 0.66$ & $39.6 \pm 0.81^{\star}$ \\
\hline
\end{tabular}


The analysis of indices of higher nervous activity showed that Cortineff introduction led to deviations in the average values for the "elementary" components of behavior, reliable differences were in increasing the grooming time and reducing the number of struts in animals of the experimental group (Table 4).

Table 2. Cortineff effect on pregnant rats on gravimetric and morphometric cerebral indices of their 40-day offspring

\begin{tabular}{|c|c|c|}
\hline Indicator & $\begin{array}{l}\text { Intact } \\
(n=24)\end{array}$ & $\begin{array}{l}\text { Cortineff } \\
\text { injection } \\
(n=41) \\
\end{array}$ \\
\hline Body weight, g & $79.6 \pm 3.70$ & $84.4 \pm 3.46$ \\
\hline Brain mass, abs., mg & $1486 \pm 13.3$ & $1500 \pm 16.0$ \\
\hline Hemispheric mass, mg & $538 \pm 7.2$ & $546 \pm 5.8$ \\
\hline Brain mass, el., mg/g & $19 \pm 0.7$ & $18 \pm 0.5$ \\
\hline Thickness of brain cortex OLP, $\mu \mathrm{m}$ & $1432 \pm 12.9$ & $1512 \pm 8.9^{*}$ \\
\hline Thickness of 1 OLP layer, $\mu \mathrm{m}$ & $135 \pm 2.8$ & $142 \pm 1.1^{\star}$ \\
\hline \multicolumn{3}{|l|}{$\begin{array}{l}\text { Number of neurons in OLP field of } \\
\text { view: }\end{array}$} \\
\hline -II layer & $19.0 \pm 0.27$ & $21.1 \pm 0.31^{\star}$ \\
\hline -V layer & $7.3 \pm 0.21$ & $6.9 \pm 0.09$ \\
\hline \multicolumn{3}{|l|}{ Section area, $\mu \mathrm{m} 2, \mathrm{OLP}$} \\
\hline - nuclei of neurons of layer II & $2.1 \pm 0.05$ & $2.2 \pm 0.04$ \\
\hline - nucleus of layer II neurons & $59.7 \pm 1.26$ & $55.3 \pm 0.85^{\star}$ \\
\hline -cytoplasm of layer II neurons & $51.0 \pm 1.84$ & $51.8 \pm 1.27$ \\
\hline - nuclei of neurons of layer $V$ & $3.0 \pm 0.14$ & $3.0 \pm 0.09$ \\
\hline - nucleus of $\vee$ layer neurons & $81.2 \pm 3.46$ & $74.4 \pm 1.29$ \\
\hline -cytoplasm of layer V PLP neurons & $76.4 \pm 3.17$ & $77.5 \pm 1.90$ \\
\hline Brain cortex thickness PLP, $\mu \mathrm{m}$ & $1230 \pm 15.4$ & $1259 \pm 6.7$ \\
\hline Thickness of 1 PLP layer, $\mu \mathrm{m}$ & $124 \pm 2.2$ & $128 \pm 1.5$ \\
\hline \multicolumn{3}{|l|}{$\begin{array}{l}\text { Number of neurons in PLP field of } \\
\text { view: }\end{array}$} \\
\hline -II layer & $19.7 \pm 0.33$ & $21.9 \pm 0.22^{*}$ \\
\hline -V layer & $6.8 \pm 0.19$ & $7.0 \pm 0.08$ \\
\hline \multicolumn{3}{|l|}{ Section area, $\mu \mathrm{m} 2, \mathrm{PLP}$} \\
\hline - nuclei of neurons of layer II & $2.0 \pm 0.06$ & $2.2 \pm 0.04^{*}$ \\
\hline - nucleus of layer II neurons & $53.9 \pm 1.07$ & $53.8 \pm 0.93$ \\
\hline -cytoplasm of layer II neurons & $48.1 \pm 1.95$ & $49.4 \pm 1.45$ \\
\hline - nuclei of neurons of layer $V$ & $2.7 \pm 0.10$ & $2.9 \pm 0.08$ \\
\hline - nucleus of $\vee$ layer neurons & $75.4 \pm 2.19$ & $73.1 \pm 1.23$ \\
\hline -cytoplasm of layer $V$ neurons & $70.2 \pm 3.22$ & $74.9 \pm 1.96$ \\
\hline -hippocampal neuronal nuclei & $2.1 \pm 0.05$ & $2.3 \pm 0.06^{*}$ \\
\hline -hippocampal neuronal nuclei & $61.9 \pm 1.68$ & $59.3 \pm 1.10$ \\
\hline -hippocampal neuronal cytoplasm & $55.3 \pm 1.89$ & $56.3 \pm 1.69$ \\
\hline
\end{tabular}

Table 3. Cortineff effect on pregnant rats on histochemical parameters of the brain their 40-day offspring

\begin{tabular}{|c|c|c|}
\hline Index & $\begin{array}{l}\text { Intact } \\
(n=24)\end{array}$ & $\begin{array}{l}\text { Cortineff } \\
\text { injection }(n=41)\end{array}$ \\
\hline \multicolumn{3}{|l|}{$\begin{array}{l}\text { Activity of NADH - } \\
\text { dehydrogenase in } \\
\text { neurons, arb . units: }\end{array}$} \\
\hline - Il layer of the neocortex & $0.859 \pm 0.028$ & $0.863 \pm 0.017$ \\
\hline - $V$ layer of the neocortex & $0.859 \pm 0.025$ & $0.876 \pm 0.018$ \\
\hline - hippocampal & $0.803 \pm 0.027$ & $0.862 \pm 0.019$ \\
\hline \multicolumn{3}{|l|}{$\begin{array}{l}\text { Activity of NADPH - } \\
\text { dehydrogenase in } \\
\text { neurons, arb. units: }\end{array}$} \\
\hline - Il layer of the neocortex & $0.806 \pm 0.041$ & $0.837 \pm 0.017$ \\
\hline - $\mathrm{V}$ layer of the neocortex & $0.813 \pm 0.027$ & $0.835 \pm 0.017$ \\
\hline - hippocampal & $0.798 \pm 0.028$ & $0.857 \pm 0.023$ \\
\hline \multicolumn{3}{|l|}{$\begin{array}{l}\text { Concentration of nucleic } \\
\text { acids, standard units, II } \\
\text { layer of the neocortex } \\
\text { OLP: }\end{array}$} \\
\hline -in the nucleoli of neurons & $0.471 \pm 0.020$ & $0.546 \pm 0.014$ * \\
\hline -in the nuclei of neurons & $0.254 \pm 0.015$ & $0.304 \pm 0.008$ * \\
\hline $\begin{array}{l}\text {-in the cytoplasm of } \\
\text { neurons }\end{array}$ & $0.300 \pm 0.016$ & $0.386 \pm 0.013$ * \\
\hline \multicolumn{3}{|l|}{$\begin{array}{l}\text { Layer } V \text { of the } \\
\text { OLP neocortex: }\end{array}$} \\
\hline -in the nucleoli of neurons & $0.497 \pm 0.022$ & $0.583 \pm 0.015$ * \\
\hline -in the nuclei of neurons & $0.247 \pm 0.016$ & $0.297 \pm 0.011^{*}$ \\
\hline $\begin{array}{l}\text {-in the cytoplasm of } \\
\text { neurons }\end{array}$ & $0.340 \pm 0.019$ & $0.429 \pm 0.015$ * \\
\hline \multicolumn{3}{|l|}{$\begin{array}{l}\text { Concentration of nucleic } \\
\text { acids, standard units, layer } \\
\text { II of the neocortex PLP: }\end{array}$} \\
\hline -in the nucleoli of neurons & $0.433 \pm 0.020$ & $0.549 \pm 0.017$ * \\
\hline -in the nuclei of neurons & $0.255 \pm 0.011$ & $0.304 \pm 0.014$ * \\
\hline $\begin{array}{l}\text {-in the cytoplasm of } \\
\text { neurons }\end{array}$ & $0.305 \pm 0.014$ & $0.376 \pm 0.016$ * \\
\hline \multicolumn{3}{|l|}{$\begin{array}{l}\text { Layer } V \text { of } \\
\text { the PLP neocortex: }\end{array}$} \\
\hline -in the nucleoli of neurons & $0.436 \pm 0.014$ & $0.562 \pm 0.018$ * \\
\hline -in the nuclei of neurons & $0.222 \pm 0.014$ & $0.291 \pm 0.012$ * \\
\hline $\begin{array}{l}\text {-in the cytoplasm of } \\
\text { neurons }\end{array}$ & $0.305 \pm 0.016$ & $0.416 \pm 0.018$ * \\
\hline Hippocampal: & & \\
\hline
\end{tabular}




\begin{tabular}{|l|l|l|}
\hline -in the nucleoli of neurons & $0.500 \pm 0.020$ & $0.608 \pm 0.026$ * \\
\hline -in the nuclei of neurons & $0.294 \pm 0.012$ & $0.380 \pm 0.020$ * \\
\hline $\begin{array}{l}\text {-in the cytoplasm of } \\
\text { neurons }\end{array}$ & $0.366 \pm 0.014$ & $0.440 \pm 0.023$ * \\
\hline
\end{tabular}

*-differences between the experimental and control groups are valid

Table 4. Cortineff effect on pregnant rats on the indicators of behavior in the PCL of their 30-day offspring

\begin{tabular}{|l|l|l|}
\hline \multicolumn{1}{|c|}{ Group } & $\begin{array}{l}\text { Intact } \\
(\mathrm{n}=24)\end{array}$ & $\begin{array}{l}\text { Cortineff } \\
\text { injection } \\
(\mathrm{n}=41)\end{array}$ \\
\hline Indicator & & \\
\hline - inaction & $14.51 \pm 3.76$ & $10.07 \pm 2.44$ \\
\hline -hanging & $3.41 \pm 0.67$ & $4.66 \pm 0.64$ \\
\hline - stable & $7.72 \pm 0.97$ & $5.79 \pm 0.91$ \\
\hline - grooming & $7.53 \pm 0.99$ & $12.23 \pm 1.81^{\star}$ \\
\hline -smell & $157.95 \pm 4.25$ & $157.69 \pm 2.78$ \\
\hline -movements & $96.34 \pm 7.23$ & $98.01 \pm 5.27$ \\
\hline - finding in open sleeves & $33.34 \pm 5.34$ & $41.06 \pm 5.45$ \\
\hline -being in closed sleeves & $144.62 \pm 5.30$ & $137.41 \pm 5.48$ \\
\hline Number & & \\
\hline -hanging & $3.54 \pm 0.60$ & $4.90 \pm 0.63$ \\
\hline - stable & $9.08 \pm 0.92$ & $6.17 \pm 0.49 *$ \\
\hline - grooming & $5.71 \pm 0.61$ & $4.90 \pm 0.38$ \\
\hline -smell & $6.00 \pm 0.61$ & $5.53 \pm 0.35$ \\
\hline -movements & $11.45 \pm 1.02$ & $12.75 \pm 0.83$ \\
\hline - finding in open sleeves & $2.00 \pm 0.23$ & $2.07 \pm 0.21$ \\
\hline -being in closed sleeves & $2.62 \pm 0.25$ & $2.87 \pm 0.21$ \\
\hline - research activity & $5.39 \pm 1.67$ & $8.96 \pm 1.96$ \\
\hline -the level of anxiety & $126.48 \pm 22.81$ & $112.49 \pm 17.26$ \\
\hline$*$ differes between groups ar & valid & \\
\hline
\end{tabular}

$*$ - differences between groups are valid

\section{CONCLUSIONS}

Thus, the obtained data are somewhat consistent with the researches data that medications with mineralocorticoid activity injected to pregnant females are able to accelerate the processes of neocortex formation, differentiation of neurons in it, to stimulate the development of macroglia cells in one-day offspring of rats. The revealed effects of Cortineff administration can be associated with both the anabolic properties of mineralocorticoids and the direct effect of the drug on cells of the forming brain that have receptors to these hormones.

At the same time, when studying the effect of Cortineff, we did not reveal its stimulating effect on brain mass growth. In addition, a decrease in the size of nuclei was found in the experimental group in neocortex neurons, which can be regarded as evidence of suppression of synthetic processes in them, neuronogenesis processes.

In general, the obtained data characterize some immediate and distant consequences of Cortineff to pregnant rats on morphometric and functional characteristics of the brain in their offspring.

\section{REFERENCES}

[1] M.S. Mitskevich, Hormonal regulation in animal ontogenesis, Science, Moscow, 1978, 224 p.

[2] B.Ya. Ryzhavsky, Brain development: the longterm consequences of the influence of uncomfortable conditions, 2006, $232 \mathrm{p}$.

[3] B.Ya. Ryzhavsky, Brain development: the longterm consequences of the influence of uncomfortable conditions, Publ. House of FESMU, Khabarovsk, 2009, 278 p.

[4] S.G. Matthews, Pediatr. Res. 47(3) (2000) 291300 .

[5] L.A.M. Welberg, J. Neuroendocrinol. 1(13) (2001) 113-128.

[6] N.E. Ordyan, A.Yu. Galeeva, S.G. Pivina, Bull. of experim. Biol. and med. 146(8) (2008) 139-143.

[7] N.N. Nikolaeva, Vidal Handbook, 2003, 1488 p.

[8] Yu.A. Sapozhnikov, Yu.I. Feldsherov, B.Ya. Ryzhavsky, Far. East med. J. 4 (2002) 25-28. 